\title{
Curcumin suppresses intestinal microvascular endothelial cells invasion and angiogenesis induced by activated platelets
}

\author{
SU XU ${ }^{1 *}$, ZHAO-XIU XU ${ }^{2 *}$, SHUAI YAN ${ }^{3 *}$, JIN LE $^{1 *}$, HAO CHEN $^{4}$, LAN MING $^{1}$, SHU-GUANG XU ${ }^{1}$ and TAO LIN ${ }^{1}$ \\ ${ }^{1}$ Department of Anorectal Surgery, Yancheng Hospital of Traditional Chinese Medicine Affiliated to Nanjing University of \\ Chinese Medicine, Yancheng, Jiangsu 224001; ${ }^{2}$ Department of Colorectal Surgery, Kongjiang Hospital of Yangpu, \\ Shanghai 200433; ${ }^{3}$ Department of Anorectal Surgery, Suzhou Hospital of Traditional Chinese Medicine, \\ Suzhou, Jiangsu 215009; ${ }^{4}$ Department of Anorectal Surgery, Zhongda Hospital, \\ Southeast University, Nanjing, Jiangsu 210009, P.R. China
}

Received July 5, 2018; Accepted May 9, 2019

DOI: $10.3892 /$ etm.2019.7662

\begin{abstract}
The present study investigated the effects and mechanism by which curcumin suppresses intestinal microvascular endothelial cells (INMECs) invasion and angiogenesis induced by activated platelets. INMECs were obtained from healthy rats, and divided into five groups: Control, platelets, platelets $+2.5 \mu \mathrm{M}$ curcumin, platelets $+5.0 \mu \mathrm{M}$ curcumin and platelets $+10.0 \mu \mathrm{M}$ curcumin. Curcumin toxicity was determined and vascular endothelial growth factor (VEGF) concentrations of the five groups were measured using ELISA. The branch point numbers were measured using a capillary tube formation experiment, invasion cell numbers were evaluated with the Transwell assay, relative protein expression levels were measured with western blot assay and immunofluorescence staining of the nucleus. The 2.5, 5 and $10 \mu \mathrm{M}$ curcumin concentrations were found to be suitable for INMECs. Curcumin significantly downregulated VEGF concentration, suppressed vascular lumen formation and inhibited invasion cell numbers in a dose-dependent manner. The $\alpha$-smooth muscle actin, collagen I, E-cadherin, phosphorylated (p-) phosphoinositide 3-kinase (PI3K), p-protein kinase B (AKT), p-mammalian target of rapamycin (m-TOR) and hypoxia inducible factor subunit alpha (HIF-1 $\alpha$ ) protein expression levels of the curcumin-treated groups were significantly downregulated in a dose-dependent manner compared with the platelet group. HIF-1 $\alpha$ protein expression levels in the nucleus of the curcumin-treated groups were significantly suppressed in a dose-dependent manner compared with the
\end{abstract}

Correspondence to: $\mathrm{Dr} \mathrm{Su} \mathrm{Xu}$, Department of Anorectal Surgery, Yancheng Hospital of Traditional Chinese Medicine Affiliated to Nanjing University of Chinese Medicine, 53 People's Road, Yancheng, Jiangsu 224001, P.R. China

E-mail: xusu20180228@163.com

Key words: curcumin, intestinal microvascular endothelial cells, phosphoinositide 3-kinase, protein kinase B, mammalian target of rapamycin platelet group. In conclusion, curcumin suppressed INMEC invasion and angiogenesis induced by activated platelets via inhibiting the activation of the PI3K/AKT/mTOR pathway.

\section{Introduction}

Crohn's Disease (CD) is a chronic recurrent inflammatory disease affecting the digestive tract. The aetiology and pathogenesis of CD remains not fully understood. However, the consensus is that intestinal mucosal immune regulation, lymphangiogenesis and intestinal mucosal barrier damage are involved in the development of CD $(1,2)$. A crucial area of current research has been the identification of effective drug components for CD treatment. Curcumin, one of the most popular traditional medicines, is a natural phenolic substance extracted from the rhizome of Curcuma longa. It has widely been used as a traditional herb in China and Southeast Asian countries for thousands of years. Recent studies have confirmed that curcumin possesses several pharmacological properties including antioxidant, anti-inflammatory and antitumour abilities; it also promotes wound healing, is spasmodic, serves as an anticoagulant and provides liver protection (3-5). Several clinical and animal experiments have reported that curcumin has beneficial therapeutic effects on inflammatory bowel disease with few adverse effects. Therefore, curcumin possesses substantial potential for clinical application (6-9); however the effects and mechanism of curcumin in CD treatment remain unclear. The present study determined suitable curcumin concentrations for further experimentation in cells using MTT assay. Then the effects of curcumin on suppressing angiogenesis and cell invasion were determined. Finally, the mechanisms by which curcumin can be used to treat $C D$ were investigated by measuring relative protein expression levels using western blot analysis and immunofluorescence staining.

\section{Materials and methods}

Experimental materials. A total of 12 Male Wistar rats of specific pathogen-free grade (weight, 300-350 g; 8.0 0 0.5 week age) were purchased from Zhejiang Experimental Animal Center (no. 170525003; animal licence no. SCXK 2014-0001) 
and supplied by the Experimental Animals Center of Nanjing University of Chinese Medicine (Nanjing, China). The animals were housed in controlled conditions (temperature, $23 \pm 2^{\circ} \mathrm{C}$; humidity, $45-60 \%$; 12-h light/dark cycle; free access to water and a standard diet). Adenosine diphosphate (ADP) was purchased from Sigma-Aldrich (Merck KGaA, Darmstadt, Germany). Foetal bovine serum and RPM 11650 culture medium were purchased from Gibco (Thermo Fisher Scientific, Inc., Waltham, MA, USA). Curcumin, activated platelets and MTT kit were purchased from Sigma-Aldrich (Merck KGaA). Total protein and Nuclear Protein Extraction kits were purchased from Sigma-Aldrich. The vascular endothelial growth factor (VEGF) ELISA kit (cat. no. 20170320; Wuhan Huamei Bioengineering Co., Ltd., Wuhan, China), anti- $\alpha$-smooth muscle actin (SMA; cat. no. 19245; Cell Signaling Technology, Inc., Danvers, MA, USA), anti-collagen I (cat. no. ab90395; Abcam, Cambridge, UK), anti-E-cadherin (cat.no.3195; Cell Signaling Technology,Inc.), anti-VEGF (cat. no. 13689-1; Wuhan Sanying Biotechnology, Wuhan, China), anti-phosphoinositide 3-kinase (PI3K; cat. no. 21890-1; Wuhan Sanying Biotechnology), anti-phosphorylated (p-) PI3K (cat. no. 4228; Cell Signaling Technology, Inc.), anti-protein kinase B (AKT; cat. no. 60203-2; Wuhan Sanying Biotechnology), anti-p-AKT (cat. no. 4060; Cell Signaling Technology, Inc.), anti-mammalian target of rapamycin (mTOR; cat. no. ab32028; Abcam), anti-p-mTOR (cat. no. ab84400; Abcam), anti-hypoxia inducible factor subunit $\alpha$ (HIF-1 $\alpha$; cat. no. ab51608; Abcam), anti-laminin subunit beta 1 (LAMB1; cat. no. 109293; Abcam) and anti-GAPDH (cat. no. 10494-1; Wuhan Sanying Biotechnology) were purchased from the respective suppliers. This study was approved by the Ethics Committee of Nanjing University of Chinese Medicine (approval no. 2017011001).

INMEC isolation and culture. INMECs were isolated following the methods described in a previous review (10). INMECs, at fourth or fifth passage, were cultured in the RPM 11650 culture medium containing 10\% FBS and used for the following experiments.

MTT assay. Cells in the logarithmic growth phase were inoculated in a 96-well plate and routinely cultured until cell adherence was observed. Curcumin solution at concentrations of $0,0.625,1.25,2.5,5,10,20$ and $40 \mu \mathrm{M}$ were added to the samples for $4 \mathrm{~h}$. Then the supernatant was removed and $200 \mu \mathrm{l}$ dimethyl sulfoxide was added to each well. The samples were placed on a rocking bed at low-speed oscillation for $1 \mathrm{~min}$. The absorbance values were measured at $490 \mathrm{~nm}$ wavelength and the cell viability of the different groups was measured. The experiment was repeated three times.

Cell grouping. According to the MTT assay result, INMECs were randomly divided into the following groups: Control, platelets and three different concentrations of curcumin-treated groups $(2.5,5$ and $10 \mu \mathrm{M})$. The INMECs were cultured at a density of $1 \times 10^{4}$ cells/well for $4 \mathrm{~h}$. The supernantants of the different groups were collected following centrifugation to measure VEGF concentrations then cells were collected for further experiments. The experiment was repeated three times.
ELISA. INMECs were treated with $25 \mu \mathrm{M}$ ADP for $24 \mathrm{~h}$ at room temperature, followed by the curcumin treatment of various concentrations. Culture medium was collected and centrifuged at $10,000 \mathrm{x}$ g for $5 \mathrm{~min}$ at $4^{\circ} \mathrm{C}$. The VEGF concentrations of the groups were measured with an ELISA kit at $490 \mathrm{~nm}$ according to the supplier's instructions. Each group was assigned nine wells.

Capillary tube formation experiment. Matrigel matrix glue was added to a 48 -well culture plate at $37^{\circ} \mathrm{C}$ for $30 \mathrm{~min}$. INMECs were added to wells at a density of $1 \times 10^{5}$ cells/well. Normal serum, normal serum containing activated platelets and three different curcumin concentrations $(2.5,5$ and $10 \mu \mathrm{M})+$ normal serum containing activated platelets were added to wells and cultured for $12 \mathrm{~h}$. An inverted microscope was used to observe and photograph capillary tube formation, and Image J v.6.0 software (National Institutes of Health, Bethesda, MD, USA) was used to quantitatively analyse cavity formation length. Each group included three replicates. Five fields were selected for each well, and the experiment was repeated three times.

Transwell invasion assay. Transwell chambers in a 24 -well plate were used for the Transwell invasion assay. For each sample, the surface of the membrane was evenly spread with Dulbecco's modified Eagle's medium (DMEM)-diluted Matrigel containing a diluted growth factor (Matrigel:DMEM, $1: 4, \mathrm{v} / \mathrm{v})$ and maintained in an incubator $\left(37^{\circ} \mathrm{C}, 5 \% \mathrm{CO}_{2}\right)$ for $30 \mathrm{~min}$ prior to cell seeding. Then $100 \mu \mathrm{l}$ of INMEC suspension $\left(1 \times 10^{5} / \mathrm{ml}\right)$ in the logarithmic growth phase was inoculated into the upper chamber and $600 \mu 1$ of serum free-DMEM was added. Each group was assigned three wells. Normal culture medium, activated platelets, activated platelets $+2.5 \mu \mathrm{M}$ curcumin, activated platelets $+5 \mu \mathrm{M}$ curcumin and activated platelets $+10 \mu \mathrm{M}$ curcumin were added to the wells and cultured for $24 \mathrm{~h}$. Cells were stained with $0.1 \%$ crystal violet (Beyotime Institute of Biotechnology) at room temperature for $5 \mathrm{~min}$, The chamber was then removed, medium discarded and samples were washed twice with PBS. Tweezers were used to place the filter membrane onto a slide plate, and five fields were randomly selected under an inverted light microscope to observe and count the number of migratory cells (magnification, x100).

Western blot analysis. INMECs were collected from the groups and the total proteins or nuclear proteins were extracted using a total protein extraction kit or nucleus protein kit respectively. The protein concentrations were quantified by bicinchoninic acid assay. In brief, $50 \mu \mathrm{g}$ protein samples were loaded/lane to perform electrophoresis with $12 \%$ SDS-PAGE then transferred to polyvinylidene difluoride membranes. Following blocking of the membranes with $5 \%$ skimmed milk at $37^{\circ} \mathrm{C}$ for $1 \mathrm{~h}$, the membranes were incubated with primary antibodies $(\alpha-$ SMA, 1:1,000; collagen I, 1:1,000; E-cadherin, 1:2,000; VEGFR, 1:1,000; PI3K, 1:1,000; p-PI3K, 1:1,000; AKT, 1:1,000; p-AKT, 1:1,000; mTOR, 1:1,000; p-mTOR, 1:1,000; HIF-1 $\alpha$, 1:1,000; LamB1, 1:2,000 and GAPDH, 1:500). The samples were incubated overnight at $4^{\circ} \mathrm{C}$ and washed thrice with PBS. Membranes were incubated with HRP-marked second antibody (1:2,000; cat. no. ab205718; Abcam, Cambridge, UK) at room temperature for $1 \mathrm{~h}$. Enhanced chemiluminescence reagent was used to visualise protein bands and band intensity 
were analysed using Image J v6.0 software (National Institutes of Health). GAPDH was used as a reference in this experiment.

Immunofluorescence staining. INMECs were inoculated into 48-well plates, and the corresponding treatments were added for $12 \mathrm{~h}$. Then cells were washed with PBS, fixed with $2 \%$ polyoxymethylene for $30 \mathrm{~min}$ and washed again with PBS (30 sec; three times) at room temperature. The cells were permeated with $1 \%$ Triton X-100 then 5\% bovine serum albumin was used to block samples at room temperature for $1 \mathrm{~h}$. HIF-1 $\alpha$ antibody $(1: 1,000$; cat. no. ab51608; Abcam) was added and samples were incubated overnight at $4^{\circ} \mathrm{C}$ then washed with PBS. Fluorescein-conjugated secondary antibody $(1: 1,000$; cat. no. ab205718) was added to samples at room temperature for $2 \mathrm{~h}$ then DAPI was used to stain the nuclei and buffered glycerol was added to mount samples. HIF-1 $\alpha$ staining was observed under a laser confocal microscope (magnification, x100) following $1 \mathrm{~h}$.

Statistical analysis. Data were presented as mean \pm standard deviation. SPSS 22.0 software (IBM Corp., Armonk, NY, USA) was used for data analysis. A one-way analysis of variance with a post hoc Dunnett's t-test was used to assess differences amongst the groups. $\mathrm{P}<0.05$ was considered to indicate statistical significance.

\section{Results}

Cell viability following treatment with different curcumin concentrations. There were no significant differences in cell viability amongst the $0,0.625,1.25,2.5,5$ and $10 \mu \mathrm{M}$ curcumin concentration groups $(\mathrm{P}>0.05$; Fig. 1$)$. However, cell viability of the 20 and $40 \mu \mathrm{M}$ curcumin concentration groups significantly decreased compared with the $0 \mu \mathrm{M}$ curcumin concentration group $(\mathrm{P}<0.001$; Fig. 1). The results demonstrated that the $0,0.625,1.25,2.5,5$ and $10 \mu \mathrm{M}$ curcumin concentrations were suitable for INMECs in this in vitro study.

VEGF concentration decreases with increasing curcumin concentration. Compared with the control group, the VEGF concentration of the platelets group was significantly upregulated ( $\mathrm{P}<0.001$; Fig. 2), indicating that activated platelets stimulated INMECs to secrete VEGF. With curcumin supplementation, the VEGF concentrations of the different curcumin-treated groups were significantly suppressed compared with the platelets group $(\mathrm{P}<0.05$; Fig. 2$)$. Furthermore, there was a significant difference in terms of VEGF concentration amongst the different curcumin concentration-treated groups (Fig. 2).

Branch point numbers decrease with increasing curcumin concentrations. There was a significantly higher branch point number in the platelets group compared with the control group $(\mathrm{P}<0.05$; Fig. 3), suggesting that activated platelets induced angiogenesis in INMECs. However, there were significantly fewer branch points in the curcumin-treated groups than in the platelets group $(\mathrm{P}<0.05$; Fig. 3$)$ with curcumin concentration exhibiting a dose-dependent association $(\mathrm{P}<0.05$; Fig. 3$)$.

Cell invasion decreases with increasing curcumin concentration. Compared with the platelets group, the $5 \mu \mathrm{M}(\mathrm{P}<0.05$; Fig. 4) and $10 \mu \mathrm{M}(\mathrm{P}<0.01$; Fig. 4$)$ curcumin-treated groups had significantly

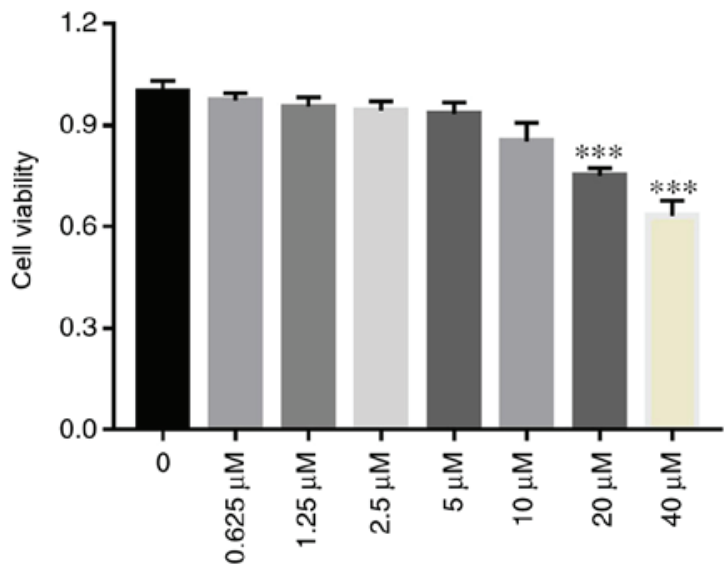

Figure 1. Intestinal microvascular endothelial cells viability in groups treated with different curcumin concentrations. ${ }^{* * *} \mathrm{P}<0.001$ vs. untreated group.

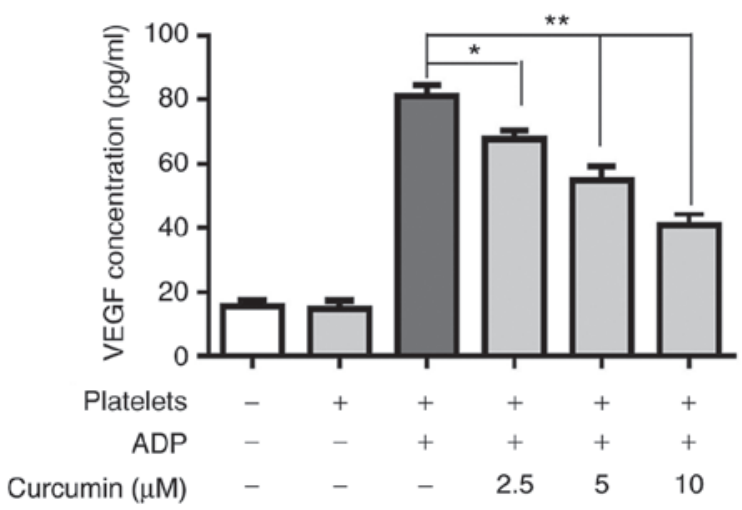

Figure 2. VEGF concentration in control, platelets and curcumin-treated groups. VEGF levels were measured in cell supernatants by ELISA. ${ }^{*} \mathrm{P}<0.05$ and ${ }^{* *} \mathrm{P}<0.01$ vs. platelets group. VEGF, vascular endothelial growth factor; ADP, adenosine diphosphate.

decreased cell invasion. These results suggested that 5 and $10 \mu \mathrm{M}$ curcumin concentrations suppressed the number of migrated INMECs in vitro.

$\alpha$-SMA, collagen I, E-cadherin and VEGFR protein expression levels following curcumin treatment. Compared with the control group, the platelets group exhibited significantly upregulated $\alpha$-SMA, collagen I and E-cadherin protein expression levels $(\mathrm{P}<0.05$; Fig. 5). However, $\alpha$-SMA, collagen I and E-cadherin protein expression levels were significantly suppressed in a dose-dependent manner in the curcumin-treated groups compared with the platelets group $(\mathrm{P}<0.05 ;$ Fig. 5$)$. There were no significant differences in VEGFR protein levels amongst the different groups ( $\mathrm{P}>0.05$; Fig. 5).

PI3K/AKT/mTOR pathway relative to HIF-1 $\alpha$ protein expression levels following curcumin treatment. There were no significant differences in PI3K, AKT and mTOR protein expression levels amongst the five groups ( $\mathrm{P}>0.05$; Fig. 6). The p-PI3K, p-AKT, p-mTOR and HIF-1 $\alpha$ protein expression levels were significantly suppressed in the curcumin-treated groups, in a dose-dependent manner, compared with the platelets group $(\mathrm{P}<0.05$; Fig. 6$)$. These results suggested that 


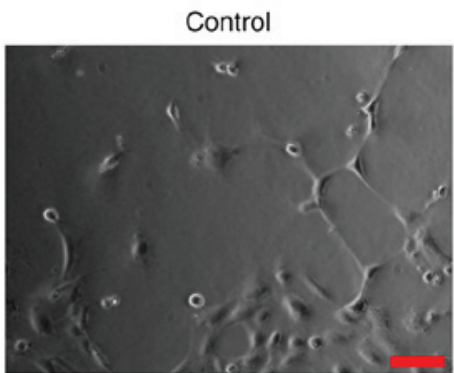

Platelets+Curcumin $5 \mu \mathrm{M}$

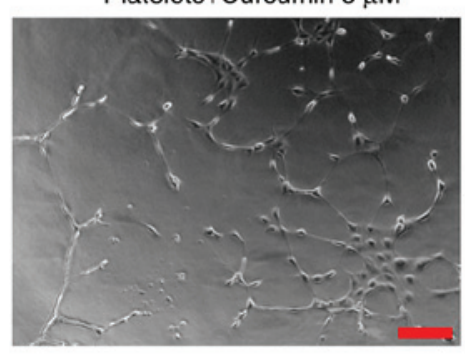

Platelets

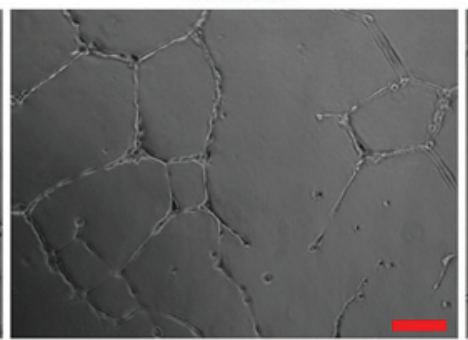

Platelets+Curcumin $10 \mu \mathrm{M}$

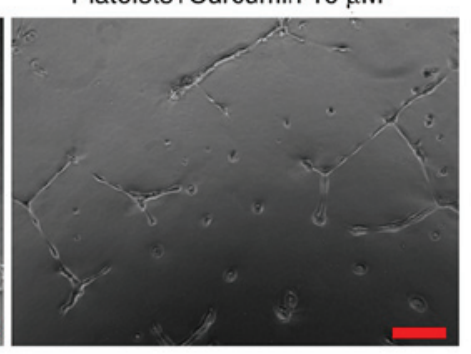

Platelets+Curcumin $2.5 \mu \mathrm{M}$
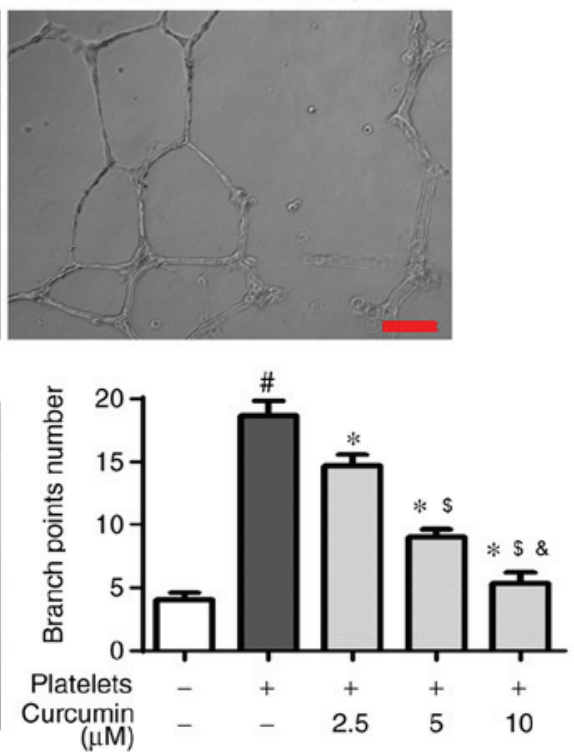

Figure 3. Branch points number in control, platelets and curcumin-treated groups. Representative photographs and quantification of branch point numbers per experimental group are shown. Scale bar, $100 \mu \mathrm{m}$. ${ }^{\#} \mathrm{P}<0.05$ vs control; ${ }^{*} \mathrm{P}<0.05$ vs. platelets group; ${ }^{\text {P }} \mathrm{P}<0.05$ vs. $2.5 \mu \mathrm{M}$ curcumin-treated group; and ${ }^{\&} \mathrm{P}<0.05$ vs. $5 \mu \mathrm{M}$ curcumin-treated group.

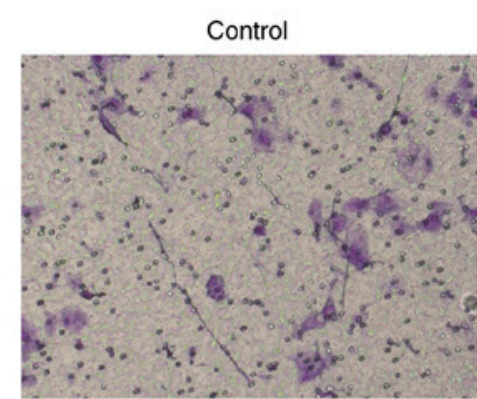

Platelet+Curcumin $5 \mu \mathrm{M}$

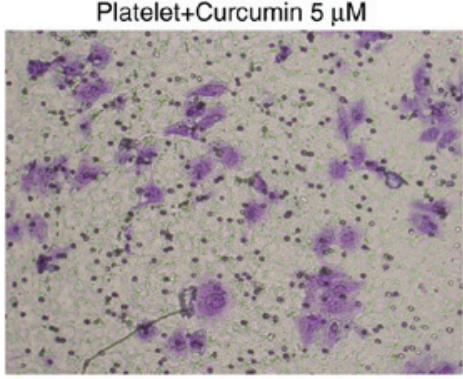

Platelet

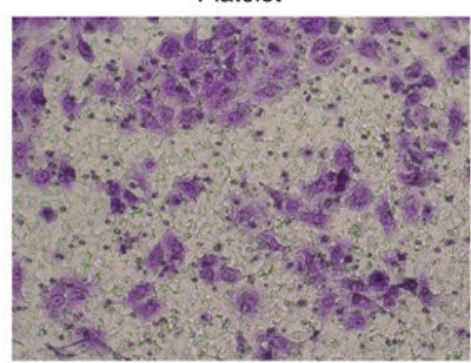

Platelet+Curcumin $10 \mu \mathrm{M}$

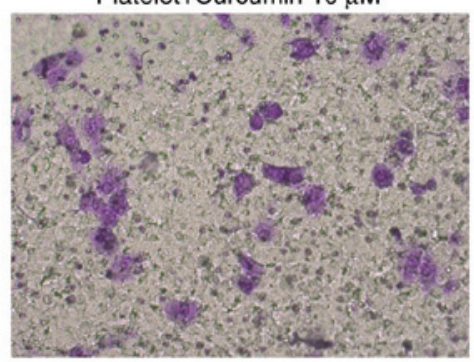

Platelet+Curcumin $2.5 \mu \mathrm{M}$
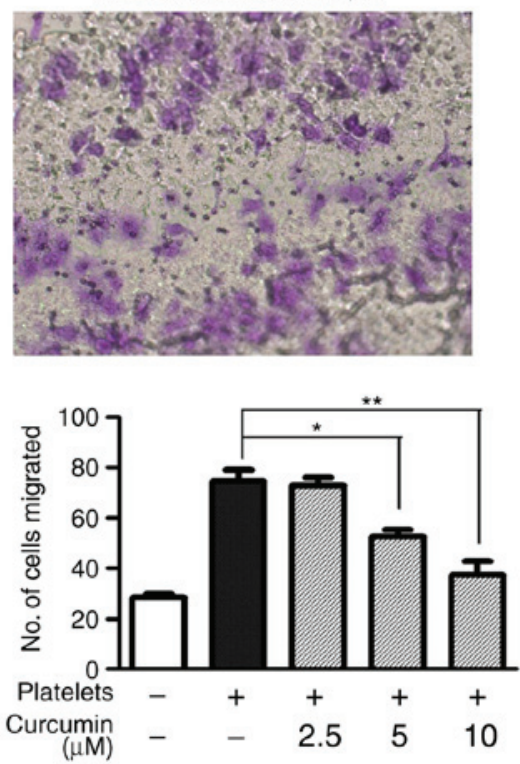

Figure 4. Intestinal microvascular endothelial cells invasion in control, platelets and curcumin-treated groups. Invasion ability was assessed by Transwell assay. " $\mathrm{P}<0.01$ and ${ }^{* *} \mathrm{P}<0.001$ vs. platelets group.

curcumin affects HIF-1 $\alpha$ by regulating phosphorylation of the $\mathrm{PI} 3 \mathrm{~K} / \mathrm{AKT} / \mathrm{mTOR}$ pathway.

HIF-1 $\alpha$ and LamB1 protein expression levels in the nucleus following curcumin treatment. Compared with the control group, the platelets group significantly upregulated HIF-1 $\alpha$ protein expression levels in the nucleus $(\mathrm{P}<0.05$; Fig. 7$)$. Curcumin treatment significantly suppressed HIF-1 $\alpha$ protein expression levels in the 5.0 and $10.0 \mu \mathrm{M}$ curcumin-treated groups $(\mathrm{P}<0.05$; Fig. 7$)$. In addition, there was a significant difference between the 5 and $10 \mu \mathrm{M}$ curcumin-treated groups ( $\mathrm{P}<0.05$; Fig. 7).
HIF-1 $\alpha$ protein nuclear translocation. The immunofluorescence staining results determined that HIF- $1 \alpha$ protein expression levels increased following stimulation with activated platelets (Fig. 8). By contrast, curcumin suppressed HIF-1 $\alpha$ protein expression levels and decreased HIF-1 $\alpha$ protein nuclear translocation in vitro (Fig. 8).

\section{Discussion}

The most commonly used drugs for the treatment of CD include aminosalicylic acid, glucocorticoids, immunosuppressive agents, inflammatory transmitter inhibitors, 

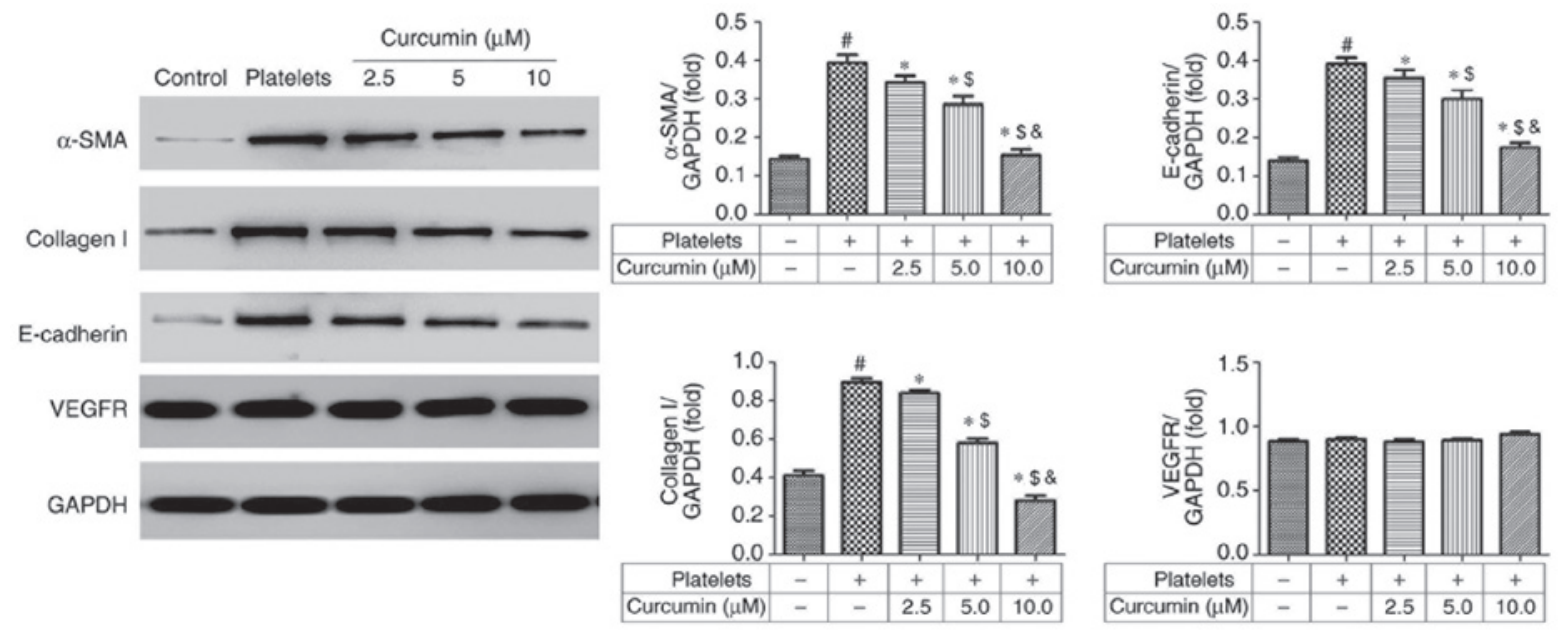

Figure 5. $\alpha$-SMA, Collagen I, E-cadherin and VEGFR protein expression in control, platelets and curcumin-treated groups. Protein expression levels were examined by western blot analysis. Representative blots and quantification relative to GAPDH are shown. ${ }^{\text {"P }}<0.05$ vs. control; " $\mathrm{P}<0.05$ vs. platelets group; ${ }^{\$} \mathrm{P}<0.05$ vs. $2.5 \mu \mathrm{M}$ curcumin-treated group; and ${ }^{\&} \mathrm{P}<0.05$ vs. $5 \mu \mathrm{M}$ curcumin-treated group. $\alpha$-SMA, $\alpha$-smooth muscle actin; VEGFR, vascular endothelial growth factor receptor.
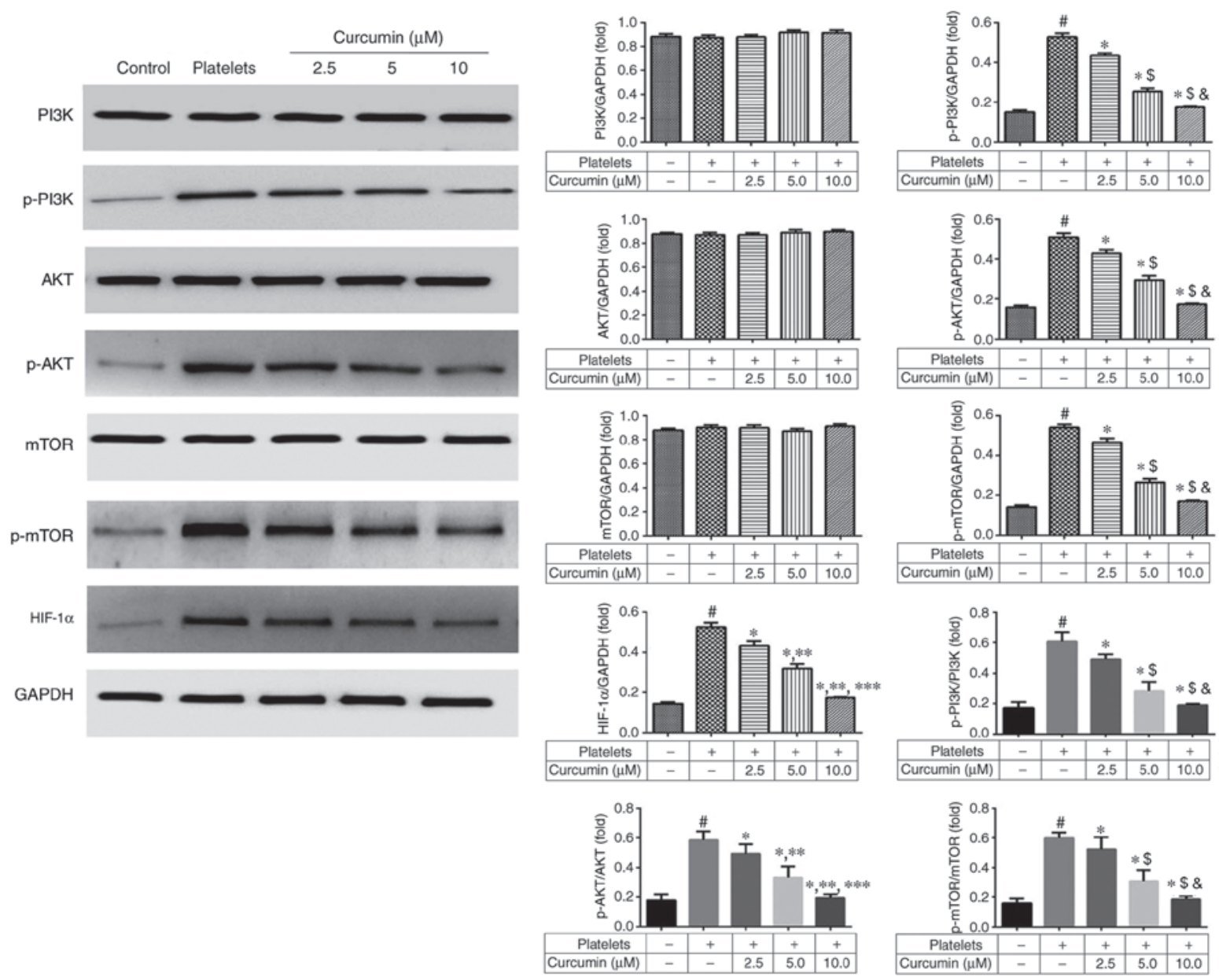

Figure 6. PI3K/AKT/mTOR pathway-related proteins and HIF-1 $\alpha$ expression in control, platelets and curcumin-treated groups. Protein expression levels were determined by western blot analysis. Representative blots and quantification are shown. ${ }^{~} \mathrm{P}<0.05$ vs control; ${ }^{*} \mathrm{P}<0.05$ vs. platelets group; ${ }^{5} \mathrm{P}<0.05$ vs. $2.5 \mu \mathrm{M}$ curcumin-treated group; and ${ }^{\&} \mathrm{P}<0.05$ vs. $5 \mu \mathrm{M}$ curcumin-treated group. PI3K, phosphoinositide 3-kinase; $\mathrm{p}-$, phosphorylated; AKT, protein kinase B; mTOR, mammalian target of rapamycin; HIF-1 $\alpha$, hypoxia inducible factor 1 subunit $\alpha$.

targeted biological immunotherapy and antibiotics (11). In the treatment of $\mathrm{CD}$, traditional Chinese medicine has been proven to be multi-channel medicines and can be used for long-term treatment of patients, with fewer adverse events $(12,13)$. During CD development, INMECs produce blood vessels induced by activated platelets (14-16). 

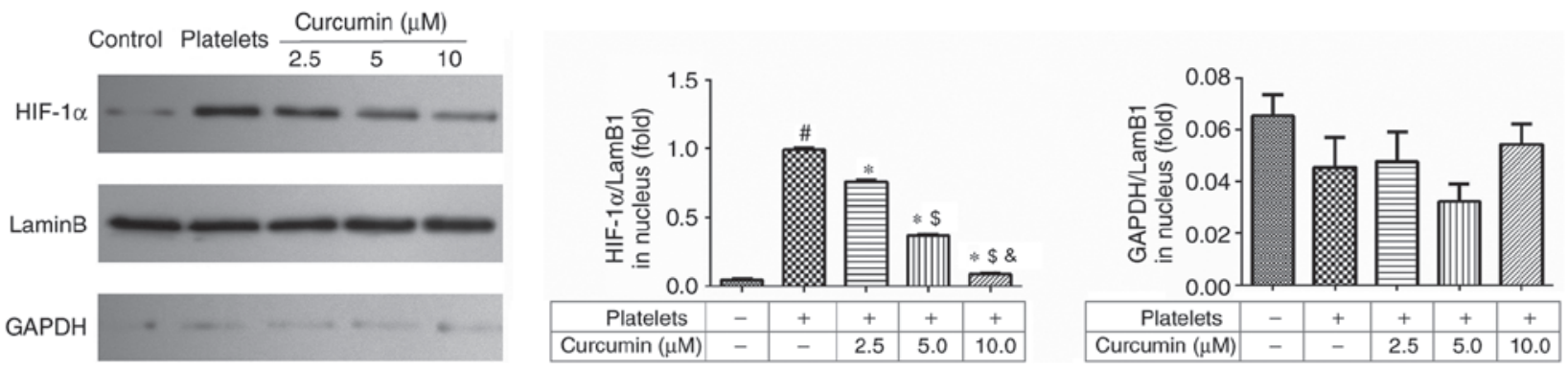

Figure 7. HIF-1 $\alpha$ and LamB1 nuclear protein expression of control, platelets and curcumin-treated groups. Protein expression levels were determined by western blot analysis. LamB1 was used as an internal control for the nuclear extracts. Representative blots and quantification are shown. ${ }^{\#} \mathrm{P}<0.05 \mathrm{vs}$. control; ${ }^{*} \mathrm{P}<0.05$ vs. platelets group; ${ }^{\$} \mathrm{P}<0.05$ vs. $2.5 \mu \mathrm{M}$ curcumin-treated group; and ${ }^{\circledR} \mathrm{P}<0.05$ vs. $5 \mu \mathrm{M}$ curcumin-treated group. HIF-1 $\alpha$, hypoxia inducible factor 1 subunit $\alpha ;$ LamB1, laminin subunit beta 1 .
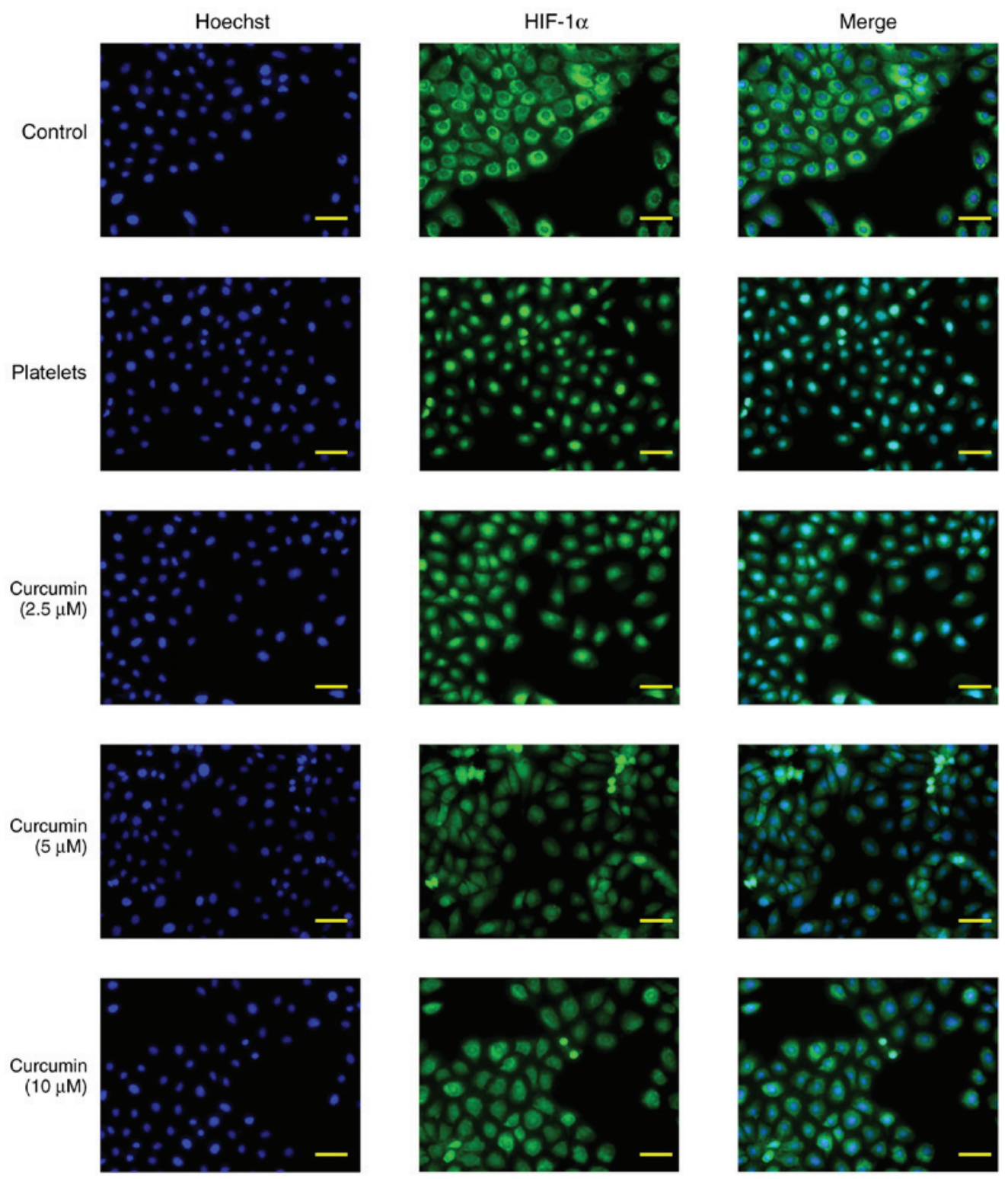

Figure 8. Immunofluorescence staining for HIF-1 $\alpha$ nuclear localization in control, platelets and curcumin-treated groups. Representative images showing staining for HIF-1 $\alpha$ (green) and the nucleus (blue). Scale bar, $100 \mu \mathrm{m}$. HIF-1 $\alpha$, hypoxia inducible factor 1 subunit $\alpha$.

Curcumin is a traditional natural drug extract that exhibits anti-inflammatory, antitumour and immunoregulation properties (17-19). However, the treatment effects of curcumin on $\mathrm{CD}$ remain unclear. Firstly, the present study evaluated the safety of curcumin on INMECs. MTT assay results demonstrated that curcumin concentrations below $20 \mu \mathrm{M}$ 
did not cause significant toxicity. The effects and mechanisms of curcumin on angiogenesis and the invasion of INMECs induced by activated platelet stimulation were then investigated. The results demonstrated that VEGF concentration was significantly reduced, branch point number was decreased and number of migrated cells were decreased with curcumin treatment in a dose-dependent manner. Finally, the relative protein expression levels were investigated to determine the mechanism of action.

Previous studies demonstrated that $\alpha$-SMA, collagen I, E-cadherin and VEGFR have key roles in cell migration (20-24). The present study demonstrated that curcumin suppressed INMEC angiogenesis and invasion by regulating $\alpha$-SMA, collagen I and E-cadherin protein expression levels. By contrast, curcumin did not have significant effects on VEGFR protein expression levels. $\alpha$-SMA, collagen I and E-cadherin genes are downstream of the HIF-1 $\alpha$ signalling pathway, therefore the upstream signalling pathway was investigated to determine the effects of curcumin in vitro.

$\mathrm{PI} 3 \mathrm{~K} / \mathrm{AKT} / \mathrm{mTOR} / \mathrm{HIF}-1 \alpha$ pathway stimulation is a crucial component in cell angiogenesis and migration, and can induce $\alpha$-SMA, collagen I and E-cadherin protein activation (25-30). The present study identified that curcumin affected phosphorylation of the PI3K/AKT/mTOR pathway; when suppressed, HIF-1 $\alpha$ total and nuclear protein expression decreased. HIF-1 $\alpha$ nuclear translocation is an essential part of the association between the PI3K/AKT/mTOR pathway and downstream genes ( $\alpha$-SMA, collagen I and E-cadherin). HIF-1 $\alpha$ nuclear translocation was observed by immunofluorescence staining with the results demonstrating that HIF-1 $\alpha$ nuclear translocation was inhibited by curcumin supplementation. In conclusion, curcumin was identified to have a dose-dependent inhibitory effect on INMEC angiogenesis and invasion induced by activated platelets, likely via inhibiting $\mathrm{PI} 3 \mathrm{~K} / \mathrm{AKT} / \mathrm{mTOR}$ pathway activation.

\section{Acknowledgements}

Not applicable.

\section{Funding}

The present study was supported by the National Natural Science Foundation of China (grant no. 81603622) and the Natural Science Foundation of Jiangsu Province of China (grant no. BK20161319).

\section{Availability of data and materials}

The datasets used and/or analyzed during the present study are available from the corresponding author on reasonable request.

\section{Authors' contributions}

SX was responsible for drafting the manuscript, as well as the acquisition, analysis and interpretation of data. ZXX collected data. SY interpreted the data. JL was responsible for drafting the manuscript. HC contributed to the study conception. LM, XGS and LT designed and supervised the current study. All authors read and approved the final manuscript.

\section{Ethics approval and consent to participate}

This study was approved by the Ethics committee of Nanjing University of Chinese Medicine (approval no. 2017011001).

\section{Competing interests}

The authors declare that they have no competing interests.

\section{References}

1. Baumgart DC and Sandborn WJ: Cronhn's disease. Lancet 380: 1590-1605, 2012

2. Liu ZJ, Yadav PK, Su JL, Wang JS and Fei K: Potential role of Th17 cells in the pathogenesis of inflammatory bowel disease. World J Gastroenterol 15: 5784-5788, 2009.

3. Ramsewak RS, DeWitt DL and Nair MG. Cytotoxicity, antioxidant and anti-inflammatory activities of curcumins I-III from Curcuma longa. Phytomedicine 7: 303-308, 2000.

4. Aggarwal BB and Harikumar KB: Potential therapeutic effects of curcumin, the anti-inflammatory agent, against neurodegenerative, cardiavascular, pulmonary, metabolic, autoimmune and neoplastic disease. Int J Biochem Cell Biol 41: 40-59, 2009.

5. Yadav VR, Suresh S, Devi K and Yadav S: Effect of cyclodextrin complexation of curcumin on its solubility and antiangiogenic and anti-inflammatory activity in rat colitis model. AAPS PharmSciTech 10: 752-762, 2009.

6. Salh B,Assi K, Templeman V,Parhar K, Owen D, Gómez-Muñoz A and Jacobson K: Curcumin attenuates DNB-induced murine colitis. Am J Physiol Gastrointest Liver Physiol 285: G235-G243, 2003.

7. Venkataranganna MV, Rafiq M, Gopumadhavan S, Peer G, Babu UV and Mitra SK: NCB-02 (standardized Curcumin preparation) protects dinitrochlorobenzene-induced colitis through down-regulation of NFkappa-B and iNOS. World $\mathrm{J}$ Gastroenterol 13: 1103-1107, 2007.

8. Hanai H, Iida T, Takeuchi K, Watanabe F, Maruyama Y, Andoh A, Tsujikawa T, Fujiyama Y, Mitsuyama K, Sata M, et al: Curcumin maintenance therapy for ulcerative colitis: Randomized, multicenter, double-blind, placebo-controlled trial. Clin Gastroenterol Hepatol 4: 1502-1506, 2006.

9. Holt PR, Katz S and Kirshoff R: Curcumin therapy in inflammatory bowel disease: A pilot study. Dig Dis Sci 50: 2191-2193, 2005.

10. Kohn EA, Du Z, Sato M, Van Schyndle CM, Welsh MA, Yang YA, Stuelten CH, Tang B, Ju W, Bottinger EP and Wakefield LM: A novel approach for the generation of genetically modified mammary epithelial cell cultures yields new insights into TGF $\beta$ signaling in the mammary gland. Breast Cancer Res 12: R83, 2010.

11. Gomollón F: Developments in the treatment of inflammatory bowel disease: 2014 overview. Gastroenterol Hepatol 37 (Suppl 3): S14-S21, 2014 (In Spanish).

12. Ng SC, Lam YT, Tsoi KK, Chan FK, Sung JJ and Wu JC: Systematic review: The efficacy of herbal therapy in inflammatory bowel disease. Aliment Pharmacol Ther 38: 854-863, 2013.

13. Rahimi R, Nikfar S and Abdollahi M: Induction of clinical response and remission of inflammatory bowel disease by use of herbal medicines: A meta-analysis. World J Gastroenterol 19: 5738-5749, 2013.

14. Leonetti D, Reimund JM, Tesse A, Viennot S, Martinez MC, Bretagne AL and Andriantsitohaina R: Circulating microparticles from Crohn's disease patients cause endothelial and vascular dysfunctions. PLoS One 8: e73088, 2013.

15. Danese S, Katz JA, Saibeni S, Papa A, Gasbarrini A, Vecchi M and Fiocchi C: Activated platelets are the source of elevated levels of soluble CD40 ligand in the circulation of inflammatory bowel disease patients. Gut 52: 1435-1441, 2003.

16. Scaldaferri F, Lancellotti S, Pizzoferrato $M$ and De Cristofaro R: Haemostatic system in inflammatory bowel diseases: New players in gut inflammation. World J Gastroenterol 17: 594-608, 2011.

17. Reddy PH, Manczak M, Yin X, Grady MC, Mitchell A, Tonk S, Kuruva CS, Bhatti JS, Kandimalla R, Vijayan M, et al: Protective effects of indian spice curcumin against amyloid- $\beta$ in Alzheimer's disease. J Alzheimers Dis 61: 843-866, 2018. 
18. Singh N, Sachdev A and Gopinath P: Polysaccharide functionalized single walled carbon nanotubes as nanocarriers for delivery of curcumin in lung cancer cells. J Nanosci Nanotechnol 18 : $1534-1541,2018$.

19. Masuelli L, Granato M, Benvenuto M, Mattera R, Bernardini R, Mattei M, d'Amati G, D'Orazi G, Faggioni A, Bei R and Cirone M: Chloroquine supplementation increases the cytotoxic effect of curcumin against Her2/neu overexpressing breast cancer cells in vitro and in vivo in nude mice while counteracts it in immune competent mice. Oncoimmunology 6: e1356151, 2017.

20. Wu KH, Ho CT, Chen ZF, Chen LC, Whang-Peng J, Lin TN and Ho YS: The apple polyphenol phloretin inhibits breast cancer cell migration and proliferation via inhibition of signals by type 2 glucose transporter. J Food Drug Anal 26: 221-23, 2018.

21. Zhang Z, Wang Y, Zhang J, Zhong J and Yang R: COL1A1 promotes metastasis in colorectal cancer by regulating the WNT/PCP pathway. Mol Med Rep 17: 5037-5042, 2018.

22. Guo H, Zhang X, Chen Q, Bao Y, Dong C and Wang X: miR-132 suppresses the migration and invasion of lung cancer cells by blocking USP9X-induced epithelial-mesenchymal transition. Am J Transl Res 10: 224-234, 2018.

23. Ogunbolude Y, Dai C, Bagu ET, Goel RK, Miah S, MacAusland-Berg J, Ng CY, Chibbar R, Napper S, Raptis L, et al: FRK inhibits breast cancer cell migration and invasion by suppressing epithelial-mesenchymal transition. Oncotarget 8: 113034-113065, 2017.

24. Wang L, Tong D, Guo Q, Wang X, Wu F, Li Q, Yang J, Zhao L, Qin Y, Liu Y and Huang C: HOXD3 targeted by miR-203a suppresses cell metastasis and angiogenesis through VEGFR in human hepatocellular carcinoma cells. Sci Rep 8: 2431, 2018.
25. Choi YH, Jin GY, Li LC and Yan GH: Inhibition of protein kinase $\mathrm{C}$ delta attenuates allergic airway inflammation through suppression of PI3K/Akt/mTOR/HIF-1 alpha/VEGF pathway. PLoS One 8: e81773, 2013.

26. Zhu Y, Tan J, Xie H, Wang J, Meng X and Wang R: HIF-1a regulates EMT via the Snail and $\beta$-catenin pathways in paraquat poisoning-induced early pulmonary fibrosis. J Cell Mol Med 20: 688-697, 2016

27. Zhang J, Zhu L, Fang J, Ge Z and Li X: LRG1 modulates epithelial-mesenchymal transition and angiogenesis in colorectal cancer via HIF-1 $\alpha$ activation. J Exp Clin Cancer Res 35: 29, 2016.

28. Baumann B, Hayashida T, Liang $X$ and Schnaper HW: Hypoxia-inducible factor- $1 \alpha$ promotes glomerulosclerosis and regulates COL1A2 expression through interactions with Smad3. Kidney Int 90: 797-808, 2016.

29. Watanabe T, Yasue A and Tanaka E: Hypoxia-inducible factor-1 $\alpha$ is required for transforming growth factor- $\beta 1$-induced type I collagen, periostin and $\alpha$-smooth muscle actin expression in human periodontal ligament cells. Arch Oral Biol 59: 595-600, 2014.

30. Yang N,Liang Y, Yang P and Ji F: Propofol suppresses LPS-induced nuclear accumulation of HIF- $1 \alpha$ and tumor aggressiveness in non-small cell lung cancer. Oncol Rep 37: 2611-2619, 2017.

This work is licensed under a Creative Commons Attribution-NonCommercial-NoDerivatives 4.0 International (CC BY-NC-ND 4.0) License. 